\title{
Investigação Qualitativa Crítica
}

\section{Critical Qualitative Inquiry}

\author{
Norman K. Denzin \\ Ph.D. em Sociologia pela Universidade de Iowa \\ Professor Emérito da Universidade do Illinois em Urbana-Champaign \\ 810 S. Wright St, 119 Gregory Hall, Urbana, IL 61802, USA \\ n-denzin@illinois.edu
}

\begin{abstract}
Resumo
Quais são as questões chave que enfrenta o chamado por um novo inquérito crítico? Como criar uma nova família de termos para uma nova investigação crítica, pois termos escorregam e deslizam, caem uns sobre os outros: crítica incorporada, transformativa, dialógica, reflexiva, participatória, emancipatória, narrativas de resistência, plateaus, planos de composição, Deleuze, Guattari, assemblages, afeto, investigação nômade, rizomática, amor, perda, práxis da escrita como uma forma de ser no mundo. Escrever de forma enquadrada em torno de atos de ativismo e resistência. Como nos movemos para frente?
\end{abstract}

\begin{abstract}
What are the key issues confronting the call for a new critical inquiry? How to create a new family of terms for a new critical inquiry, terms slip and slide, fall over one another: critical embodied, transformative, dialogic, reflexive, participatory, emancipatory, narratives of resistance, plateaus, planes of composition, Deleuze, Guattari, assemblages, affect, nomadic inquiry, rhizomatic, love, loss, praxis writing as a way of being in the world. Writing framed around acts of activism and resistance. How do we move forward?
\end{abstract}

\section{Palavras-chave}

Ética, justiça social, investigação crítica

\section{Keywords}

ethics, social justice, critical inquiry

\section{Introdução}

Cada um de nós tem a responsabilidade por conduzir pesquisas éticas que façam a diferença nas vidas daqueles cujas oportunidades de vida, saúde, segurança e bem-estar são reduzidas por condições de pobreza.

- Leslie Rebecca Bloom (2009, p. 253).

Nunca houve uma necessidade maior de uma investigação qualitativa crítica que interesse à esfera pública. Vivemos na cultura de auditoria do neoliberalismo global. A política de evidências que define a cultura de auditoria marginaliza a investigação crítica. Nosso desafio é empurrar, resistir, redefinir o lugar da academia, das epistemologias indígenas e o papel do intelectual público nos espaços públicos. Essa é uma convocação à 
pesquisa qualitativa interpretativa, crítica e performativa que importa nas vidas daqueles que vivem diariamente a injustiça social. Esta é uma convocação por investigações que abordem as desigualdades na economia, educação, emprego, meio ambiente, saúde, habitação, alimentação e acesso à água, uma investigação que abrace o clamor global pela paz e pela justiça.

Há a necessidade de desestabilizar os conceitos tradicionais do que conta como pesquisa, como evidência, como investigação legítima. Como esse tipo de trabalho pode se tornar parte da conversa pública? Quem pode falar e para quem? Como as vozes são representadas? Podemos criar novos modelos de desempenho, representação, intervenção e práxis? Podemos repensar o que queremos dizer por investigação ética? Podemos formar uma nova geração de acadêmicos engajados e líderes comunitários? O que conta como conhecimento acadêmico na esfera pública neoliberal? Podemos imaginar novos modelos de accountability e como podemos falar sobre impacto, mudança e para quem é a mudança?

A era das redes sociais apagou os entendimentos tradicionais da esfera pública, da vida privada, dos problemas pessoais e da sociedade civil. É hora de dar proeminência, interrogar, imaginar e envolver novas formas de fazer uma investigação qualitativa crítica na esfera pública neoliberal.

Qual é o papel da pesquisa qualitativa crítica em um presente histórico quando a necessidade de justiça social nunca tão grande? Este é um presente histórico que clama por visões emancipatórias, por visões que inspirem investigações transformadoras e por investigações que possam fornecer autoridade moral para mover as pessoas a lutar e resistir à opressão. A busca por justiça social dentro de um paradigma transformador desafia as formas prevalecentes de desigualdade, pobreza, opressão humana e injustiça. Este paradigma está firmemente enraizado em uma agenda de direitos humanos. Isso requer um quadro ético que seja baseado nos direitos e na justiça social. Isso requer uma consciência acerca da "necessidade de remediar as desigualdades dando prioridade (...) às vozes dos grupos menos favorecidos da sociedade" (Mertens, Holmes, \& Harris, 2009, p. 89). Isso incentiva o uso da pesquisa qualitativa para fins de justiça social, incluindo tornar essas pesquisas acessíveis para educação pública, formulação de políticas sociais e transformação comunitária.

Esta é uma visão que está aberta a inúmeras formas de se fazer um trabalho de serviços de justiça social: assistentes sociais que trabalham com clientes individuais com compaixão, estudantes de pós-graduação que atuam como tradutores de línguas para trabalhadores migrantes que não falam inglês e seus filhos, pesquisadores de saúde que colaboram com as comunidades para melhorar a prestação de sistemas de cuidados de saúde, pesquisadores qualitativos envolvendo seus alunos em visões de interesse público para a sociedade, acadêmicos indígenas treinados para trabalhar para suas próprias nações usando seus próprios valores, professores que promovem as práticas éticas da pesquisa qualitativa por meio de publicações, apresentações e ensino tradicional em sala de aula, e com desenvolvimento profissional a nível internacional e nacional (Bloom, 2009, p. 253).

Pesquisadores de investigação qualitativa crítica estão unidos no compromisso de expor e criticar as formas de desigualdade e discriminação que operam no cotidiano (Garoian \& Gaudelius, 2008). Juntos, eles procuram disciplinas e intervenções moralmente informadas que ajudarão as pessoas a transcender e superar o desespero psicológico alimentado pelas guerras, desastres econômicos e políticas sexuais e culturais desagregadoras. Como cidadãos globais, não somos mais chamados a apenas interpretar o mundo, que era a orientação da investigação qualitativa tradicional. Hoje, nós somos chamados a mudar o mundo e a transformá-lo de maneira a resistir à injustiça enquanto celebramos a liberdade e a democracia participativa plena e inclusiva.

Esse desafio mobiliza os membros da comunidade interpretativa de duas maneiras. Oferece uma resposta para aqueles que expressam dúvidas e reservas sobre pesquisa 
qualitativa, pessoas que dizem "É apenas um estudo qualitativo!". A resposta é que NÃO É APENAS UM estudo qualitativo. Esta é uma pesquisa ativista eticamente responsável. O compromisso declarado de justiça social concentra inquéritos em pesquisas que fazem diferença na vida de pessoas socialmente oprimidas.

O desejo é de se criar uma agenda eticamente responsável que tenha esses objetivos:

1. Colocar as vozes dos oprimidos no centro da investigação;

2. Usar a investigação para revelar espaços de mudança e ativismo;

3. Usar a investigação e o ativismo para ajudar as pessoas;

4. Afetar a política social fazendo-se as críticas serem ouvidas e influenciarem os decisores políticos;

5. Afetar as mudanças na vida do investigador, servindo assim de modelo de mudança para os outros (Bloom \& Sawin, 2009, pp. 338, 340-342, 344).

Vivemos num mundo dominado por números. Sabemos após uma década de crítica nos campos de saúde, bem-estar e educação que as medidas baseadas em evidências de qualidade e excelência dependem de modelos estreitos de objetividade e impacto. A reputação, a quantidade de citações e os escores de impacto dos pesquisadores não são indicadores aceitáveis de qualidade. Esses não deveriam ser os critérios que usamos para julgar nosso trabalho, ou um ao outro. Não se deveria permitir que esses critérios moldem o que fazemos.

Para isso, devemos criar nossos próprios padrões de avaliação, nossas próprias medidas de qualidade, influência, excelência e impacto de justiça social. Estes são critérios morais. Eles celebram resistência, experimentação e empoderamento. Eles honram o trabalho partidário que oferece críticas baseadas no conhecimento das configurações sociais e das instituições. Eles promovem a dignidade humana, direitos humanos e sociedades justas em todo o mundo. Esses discursos serão sempre sobre o local, sobre a justiça humana nas vidas vividas sob o neoliberalismo. $\mathrm{O}$ foco será nos seres humanos enquanto indivíduos singulares universais e nos grupos que universalizam, em suas singularidades, as experiências de vida transformadoras de seu momento histórico.

A globalização da pesquisa qualitativa crítica em um contexto internacional deveria ser sobre isso. Pode-se ver que procuro uma forma de escrita que seja performativa, dialógica, pedagógica. Nem todos os pesquisadores qualitativos endossarão a abordagem performativa e colaborativa baseada em comunidade que eu defendo. Isso só deve ser usado quando o pesquisador deseja examinar a relação entre problemas pessoais e comunitários e as políticas e instituições públicas que foram criadas para tratar dessas questões.

\section{História}

Vidich e Lyman (1994) nos lembram que a história dos métodos qualitativos foi profundamente incorporada no estudo de raça e de políticas do colonialismo. Desde suas origens no século XIX, a missão da etnografia era descobrir, estudar e registrar o modo de vida do outro primitivo de pele escura (p.25). Como a antropologia colonial do século XIX deu lugar a sociologia e antropologia urbanas do século XX, o foco mudou para estudos de assimilação, de etnografias do índio americano, do outro indígena, do outro cívico, das minorias raciais que vivem em guetos urbanos e os problemas sociais que eles causam nos sistemas de escolarização, bem-estar e cuidado de saúde.

Ao longo de sua história, os usuários da pesquisa qualitativa mostraram compromissos com um pequeno conjunto de crenças, incluindo o objetivismo e a disposição de interpretar teoricamente os comportamentos e experiências daqueles estudados (ver Hammersley, 2008). Essas crenças complementam a tradição positivista de cumplicidade com o colonialismo e a política global do capitalismo branco e patriarcal. $\mathrm{O}$ aparato positivista estuda, mas não 
consegue fazer desaparecem os problemas das políticas de justiça racial e social e o privilégio branco.

Sobre isso, estendendo W. E. B. Du Bois (1978/1901), é certo que um problema contínuo "do século XXI será... [a questão da cor] ... ou seja, a democracia moderna não pode ter êxito a menos que pessoas de diferentes raças e religiões também estejam integradas no todo democrático" (pp. 281, 288).

\section{A comunidade internacional de investigação qualitativa}

A comunidade de investigação qualitativa consiste de grupos de pessoas globalmente dispersas que estão tentando implementar uma abordagem interpretativa crítica que os ajude (e a outros) a explicar as condições aterradoras que definem a vida cotidiana na primeira década deste novo século. Esses indivíduos usam modelos de interpretação participativa, construtivista, crítica, feminista, queer, da teoria crítica de raça e estudos culturais. Eles se localizam nas fronteiras epistemológicas entre pós-positivismo e pós-estruturalismo. Eles trabalham nos centros e nas margens das disciplinas que se cruzam, desde da comunicação social até os estudos feministas, de raça, étnicos e religiosos. Da sociologia, da história, da antropologia, da crítica literária, da ciência política e da economia, até serviço social, saúde e educação.

Eles usam múltiplas estratégias de pesquisa, desde estudo de caso até etnografia, fenomenologia, grounded theory, biografia, histórico, e pesquisa clínica e participativa. Como escritores e intérpretes, esses indivíduos lutam com critérios positivistas, pós-positivistas, pósestruturais e pós-modernos para avaliar o trabalho escrito.

Claro que muito do campo ainda funciona dentro de quadros definidos por momentos históricos anteriores. Assim é como deve ser. Não existe uma via única para fazer uma pesquisa interpretativa e qualitativa. Somos todos bricoleurs interpretativos presos no presente, trabalhando contra o passado, à medida que avançamos para um futuro politicamente carregado e desafiador.

A natureza aberta do projeto de pesquisa qualitativa leva a uma resistência perpétua contra as tentativas de impor um paradigma único parecido ao guarda-chuva em todo o projeto. Existem múltiplos projetos interpretativos, incluindo o projeto metodológico decolonizador de acadêmicos indígenas, teorias marxistas de pedagogia crítica; [auto]etnografias performativas; epistemologias posicionais, teoria crítica da raça; etnografias críticas, públicas, poéticas, queer, materialistas, feministas e reflexivas; projetos conectados ao estudos culturais britânicos e à escola de Frankfurt; grounded theorists em múltiplas variedades; múltiplas vertentes da etnometodologia e projetos de estudos culturais transnacionais. $\mathrm{O}$ foco genérico de cada uma dessas versões da pesquisa qualitativa envolve uma política do local e uma política utópica de possibilidade (Madison, 1998) que corrige as injustiças sociais e imagina uma democracia radical ainda não existente (Weems, 2002, p.3).

Este é um mundo onde os textos de investigação qualitativa circulam como outras commodities em uma economia mundial eletrônica. Os processos legais, globais e locais apagaram a distância pessoal e institucional entre os etnógrafos e aqueles sobre os quais ele (ou ela) escreve. Nós não "possuímos" as notas de campo que fazemos sobre aqueles que estudamos. Não temos uma garantia incontestável para estudar ninguém ou qualquer coisa. Os sujeitos agora desafiam como eles foram escritos e mais de um etnógrafo foi levado ao tribunal.

O nosso projeto é de gênero. Os teóricos feministas, pós-coloniais e queer questionam a lógica tradicional do texto narrativo heterossexual etnográfico que posiciona reflexivamente o self neutro de gênero (ou masculino), do etnógrafo, dentro de uma história realista. Hoje, não existe uma identidade etnográfica solidificada. O etnógrafo trabalha dentro de uma realidade "híbrida". A experiência, o discurso e o auto entendimento colide contra 
pressupostos culturais maiores em relação a raça, etnia, nacionalidade, gênero, classe e idade. Uma certa identidade nunca é possível, o etnógrafo sempre deve perguntar: "não é quem sou eu?", mas "quando, onde, como estou eu?" (Marcus, 2009).

A pesquisa qualitativa é um projeto moral, alegórico e terapêutico. A etnografia é mais que o registro da experiência humana. $\mathrm{O}$ etnógrafo escreve pequenos contos morais, contos que fazem mais do que celebrar a diferença cultural, ou trazer viva outra cultura. A história do pesquisador é escrita como um suporte, um pilar, que, parafraseando William Faulkner (1967, p. 724), ajudará homens e mulheres a durar e prevalecer nos primeiros anos do século XXI.

Apesar de quebras e rupturas constantes definirem o campo da pesquisa qualitativa, há um centro de mudança no projeto: um compromisso humanístico e de justiça social professado ao estudo do mundo social a partir da perspectiva das interações do indivíduo. Desse princípio, fluem as políticas liberais e radicais de ação que são levadas à frente pelos pesquisadores feministas, clínicos, étnicos, críticos, queer e dos estudos culturais. Apesar de várias comunidades interpretativas agora circularem dentro do campo da pesquisa qualitativa, todos estão unidos por esse ponto único.

\section{História, política e paradigmas}

Para entender melhor onde estamos hoje e entender melhor as críticas atuais, é útil retornar às chamadas guerras paradigmáticas da década de 1980, as quais resultaram no sério enfraquecimento da pesquisa quantitativa em educação. Pedagogia crítica, teóricos críticos e análises feministas fomentaram lutas por poder e capital cultural para pobres, não brancos, mulheres e gays.

A história de Teddlie e Tashakkori (2003) é útil aqui. Eles expandem o período da guerra dos anos 1980. Para eles, houve pelo menos três guerras paradigmáticas ou períodos de conflito: a guerra pós-positivista-construtivista contra o positivismo (1970-1990); o conflito entre os paradigmas concorrentes pós-positivistas, construtivistas e teoria crítica (1990-2005); e o conflito atual entre os metodologistas baseados em evidências e as escolas de métodos mistos, interpretativos e da teoria crítica (2005-presente) $)^{1}$.

O diálogo de paradigma de Guba (1990a) sinalizou o fim das guerras dos anos 80. Os pós-positivistas, os construtivistas e os teólogos críticos conversaram uns com os outros, trabalhando em questões relacionadas a ética, estudos de campo, práxis, critérios, acumulação de conhecimento, verdade, significado, treinamento de pós-graduação, valores e política. No início dos anos 90, surgiu uma explosão de trabalhos publicados sobre pesquisa qualitativa, manuais e novos periódicos. Apareceram grupos de interesses especiais comprometidos com paradigmas particulares, alguns tinham inclusive seus próprios periódicos ${ }^{2}$.

O segundo conflito de paradigmas ocorreu dentro da comunidade de métodos mistos e envolveu disputas "entre indivíduos convencidos da pureza do paradigma de sua própria posição" (Teddlie \& Tashakkori, 2003, p.7). Os puristas estenderam e repetiram o argumento de que os métodos quantitativos e qualitativos que o pós-positivismo e os outros "ismos" não podem ser combinados devido às diferenças entre os seus pressupostos paradigmáticos subjacente. Na frente metodológica, a tese de incompatibilidade foi desafiada por aqueles que invocaram a triangulação como forma de combinar métodos múltiplos para estudar o mesmo

\footnotetext{
${ }^{1}$ Eles argumentam que o segundo momento, a Era de Ouro (1950-1970), foi marcada pelo desmantelamento do positivismo, a emergência do pós-positivismo e pelo desenvolvimento de desenhos de pesquisa que usam métodos mistos quantitativos e qualitativos. O conflito completo desenvolveu-se ao longo do período de 19701990, o momento da primeira "guerra paradigmática".

${ }^{2} \mathrm{O}$ conflito se deu entre as várias pedagogias de empoderamento: feminista, antirracista, radical, freireana, teologia da libertação, pós-modernistas, pós-estruturalistas, estudos culturais e demais (ver Guba \& Lincoln, 2005; Luke \& Gore, 1992; McLaren \& Kincheloe, 2007).
} 
fenômeno (Teddlie \& Tashakkori, 2003, p.7). Assim, foi inaugurado uma nova rodada de argumentos e debates sobre superioridade paradigmática.

Um paradigma pragmático suave e apolítico surgiu no período pós-1990. De repente, os métodos quantitativos e qualitativos tornaram-se compatíveis, e os pesquisadores poderiam usar ambos em suas investigações empíricas (Teddlie \& Tashakkori, 2003, p.7). Os proponentes fizeram apelos a um argumento pragmático de "o que funciona", afirmando que "não existe incompatibilidade entre métodos quantitativos e qualitativos tanto no nível prático quanto epistemológico (...), portanto, não há boas razões para os pesquisadores temerem avançar com 'o que funciona'" (Howe, 2004, p. 44). Claro, o que funciona é mais do que uma questão empírica. Isso envolve a política de evidências.

Este é um espaço aonde surge a pesquisa baseada em evidências (evidence-based research). Este é o campo de batalha do terceiro confronto. Este é o terceiro momento para Teddlie e Tashakkori, métodos mistos e investigação baseada em evidência se encontram em um espaço suavizado (soft-center). Esse é o espaço para o empirismo abstrato. A investigação rompe com a política. A biografia e a história regridem para um papel secundário. A racionalidade tecnológica prevalece.

Paradigmas Rivais. Já se passou quase meio século desde os conflitos metodológicos dos anos 1970 e 1980. Uma "ladainha" familiar de críticas pode ser facilmente resumida:

A investigação qualitativa não é científica,

A investigação qualitativa é ficção,

A investigação qualitativa é um jornalismo suave,

A investigação qualitativa é política,

A investigação qualitativa não possui critérios de verdade,

A investigação qualitativa é uma pesquisa de gabinete,

A investigação qualitativa é uma metodologia de vale-tudo,

A investigação qualitativa é o pós-modernismo romântico,

A investigação qualitativa produz apenas críticas morais,

A investigação qualitativa leva apenas a resultados de baixa qualidade,

A investigação qualitativa leva apenas a resultados estereotípicos e aproximados,

A investigação qualitativa produz apenas resultados próximos do senso comum,

A investigação qualitativa sinaliza a morte da ciência empírica,

A investigação qualitativa é um ataque à razão e à verdade,

A investigação qualitativa não é rigorosa,

A investigação qualitativa não é sistemática,

A investigação qualitativa não possui uma metodologia objetiva,

A investigação qualitativa não leva a análises causais,

A investigação qualitativa não utiliza experimentos aleatórios controlados,

A investigação qualitativa não produz trabalho que possa ser replicado,

A investigação qualitativa não produz trabalho que possa ser generalizado,

A investigação qualitativa não tem variáveis bem definidas,

A investigação qualitativa não produz evidências sólidas.

Na melhor das hipóteses, estudo de caso, entrevista e métodos etnográficos oferecem materiais descritivos que podem ser testados com métodos experimentais. As epistemologias 
de teorias críticas de raça, queer, pós-coloniais, feministas e pós-modernas tornam-se inúteis, relegadas, na melhor das hipóteses, para a categoria de erudição, e não de ciência (Ryan \& Hood, 2004, p. 81). Também é importante lembrar que as críticas às novas formas de escrita estavam ligadas à política identitária e à teoria feminista, e na antropologia às críticas póscoloniais. Essas críticas envolveram um conjunto complexo de questões, a saber, quem tinha o direito de falar para quem, e como? (Clough, 2000, p. 283).

A necessidade de representar as identidades híbridas pós-coloniais tornou-se o foco da escrita experimental na etnografia, assim como tem havido "um esforço para elaborar identidades de raça, classe, gênero e nacionalidade nas escritas auto etnográficas de teóricos pós-coloniais" (Clough, 2000, pág. 285). Esses debates sobre escrita, agência, self, subjetividade, nação, cultura, raça e gênero revelaram-se em uma paisagem global, envolvendo a transnacionalização do capital e a globalização da tecnologia (p. 279). Assim, desde o início, a escrita experimental tem sido intimamente ligada a gênero, raça, família, nação, política, capital, tecnologia, teoria social crítica e crítica cultural, ou seja, debater questões sobre conhecimento e sua representação e apresentação.

As críticas interpretativas afirmam que o positivista aprova uma visão estreita da ciência, enquanto celebra um "experimentalismo neoclássico que é um retrocesso para a era Campbell-Stanley e sua adesão dogmática a uma relação exclusiva com métodos quantitativos" (Howe, 2004, 2009, p. 42; Maxwell, 2004). As críticas interpretativas afirmam que pesquisadores baseados em evidências falham na compreensão de que todos os fatos são repletos de valor e teorias; não existe uma verdade objetiva.

Se a oposição à ciência positiva pelos pós-estruturalistas é vista como um ataque à razão e à verdade, o ataque positivista da ciência à pesquisa qualitativa é considerado uma tentativa de legislar uma versão da verdade sobre outra.

\section{Um Impasse?}

Meio século? Sim. As mesmas críticas? Sim. Alguma mudança? Sim. O que? Na época tradicional e dourada da investigação qualitativa, o positivismo reinava. Toda da investigação foi julgada frente a um conjunto estreito de critérios objetivos, validos, confiáveis para entendimento do "Outro" e seu modo de vida.

O mito do observador objetivo foi destroçado. O pesquisador qualitativo não é um observador objetivo, politicamente neutro e que se destaca do estudo do mundo social. Em vez disso, o pesquisador é situado historicamente e localmente dentro dos próprios processos em estudo. Um "self" histórico e de gênero é trazido para esse processo. Este "self", enquanto um conjunto de identidades em mudança, tem sua própria história com as práticas situadas que definem e moldam as questões públicas e os problemas privados em estudo.

Nas ciências sociais de hoje, não existe mais uma visão de Deus que garanta uma certeza metodológica absoluta. Toda consulta reflete o ponto de vista do investigador. Toda observação é carregada de teorias. Não há possibilidade de conhecimento livre de teoria ou de valor. Os dias do realismo ingênuo e do positivismo ingênuo acabaram. Os critérios para avaliar a pesquisa agora são relativos.

Uma ciência social crítica busca seu fundamento externo não na ciência, em nenhuma das suas formas revisionistas, pós positivistas, mas sim em um compromisso com a pedagogia crítica e o feminismo comunitário com esperança, mas sem garantias. Ele procura entender como o poder e a ideologia operam através e por meio de sistemas de discurso, bens culturais e textos culturais. Ele pergunta como palavras e textos e seus significados desempenham um papel fundamental nas "performances decisivas de raça, classe [e] gênero" das culturas (Downing, 1987, p. 80).

Nós não mais simplesmente escrevemos cultura. Nós desempenhamos cultura. Hoje temos muitas formas diferentes de investigação qualitativa e temos também vários critérios 
para avaliar o nosso trabalho. É um novo dia para a minha geração. Nós desenhamos nossa linha na areia, e nós podemos redesenhá-la. Mas estamos firmemente de acordo com a crença de que uma investigação qualitativa crítica inspirada pela imaginação sociológica pode tornar o mundo um lugar melhor.

\section{Mudando o Mundo}

A investigação qualitativa pode contribuir para justiça social das seguintes maneiras. Primeiro, ela pode ajudar a identificar diferentes definições de um problema e/ou de uma situação que está sendo avaliada e há algum acordo de que a mudança é necessária. Pode mostrar, por exemplo, como as esposas maltratadas interpretam os abrigos, linhas de atendimento telefônico e serviços públicos que são disponibilizados para elas por agências de assistência social. Através do uso de narrativas de experiências pessoais, as perspectivas de mulheres e trabalhadores podem ser comparadas e contrastadas.

Segundo, os pressupostos, muitas vezes desmentidos pelos fatos da experiência, que são mantidos por várias partes interessadas - decisores políticos, clientes, profissionais de saúde, profissionais on-line - podem ser localizados e mostrados como corretos ou incorretos (Becker, 1967, p. 23). Terceiro, os pontos estratégicos de intervenção em situações sociais podem ser identificados. Desta forma, os serviços de uma agência e um programa podem ser melhorados e avaliados. Quarto, é possível sugerir "pontos de vista morais alternativos a partir dos quais o problema", a política e o programa podem ser interpretados e avaliados (ver Becker, 1967, pp. 23-24). Devido à sua ênfase na experiência e nos seus significados, o método interpretativo sugere que os programas devem sempre ser julgados pelo ponto de vista das pessoas mais diretamente afetadas. Quinto, os limites das estatísticas e avaliações estatísticas podem ser expostos com os materiais mais qualitativos e interpretativos, fornecidos por essa abordagem. A sua ênfase na singularidade de cada vida mantém o caso individual como a medida da eficácia de todos os programas aplicados.

Os acadêmicos críticos estão comprometidos em mostrar como as práticas de pesquisa qualitativa crítica e interpretativa podem ajudar a mudar o mundo de maneiras positivas. Eles estão empenhados em criar novas formas de tornar as práticas de investigação qualitativa crítica central para o funcionamento de uma sociedade democrática e livre.

Este compromisso baseia-se na importância da interpretação e da compreensão como características-chave da vida social. Na vida social há apenas interpretação. Ou seja, a vida cotidiana gira em torno de pessoas que interpretam e fazem julgamentos sobre comportamentos e experiências próprios e dos outros. Muitas vezes, essas interpretações e julgamentos são baseados em entendimentos incorretos. As pessoas, por exemplo, confundem suas próprias experiências com as experiências dos outros. Essas interpretações são então formuladas em programas sociais que visam alterar e moldar a vida das pessoas problemáticas, como por exemplo, serviços comunitários para os doentes mentais ou semteto, os centros de tratamento de alcoólatras e serviços médicos para pacientes com AIDS.

Mas, muitas vezes, os entendimentos sobre os quais esses programas se baseiam têm pouca relação com os significados, interpretações e experiência das pessoas às quais estão destinados a servir. Como consequência, há uma lacuna ou falha na compreensão. Os programas não funcionam porque eles são baseados em uma falha na perspectiva e na atitude da pessoa atendida. É função das disciplinas humanas e das ciências sociais aplicadas esclarecer como as interpretações e os entendimentos são formulados, implementados e como o significado é dado em situações problemáticas e vividas. Idealmente, esse conhecimento também pode ser usado para avaliar programas que foram implementados para ajudar as pessoas com problemas. As perspectivas e experiências das pessoas que são atendidas por programas de justiça social devem ser apreendidas, interpretadas e compreendidas para que programas aplicados, sólidos, efetivos, sejam criados. 


\section{Ciência de quem, Pesquisa de quem}

Não podemos permitir que o novo campo positivista do SBR (Science Based Research) reivindique o controle sobre a palavra ciência, assim como devemos reivindicar o controle sobre o que queremos dizer com pesquisa (Hammersley, 2008). Eisenhart e Jurow (2011) propõem um modelo de ciência qualitativa que seja interpretativo e prático. Da mesma forma, os modelos de ciência queer, feministas, indígenas e pós-coloniais abrem espaços adicionais para resistir à estrutura estreita e hegemônica de um framework de pesquisa SBR (Denzin, 2013; Koro-Ljungberg \& Maclure, 2013; St. Pierre, 2011).

Nós precisamos encontrar novas formas estratégicas e táticas de trabalhar um com o outro em um novo "novo" paradigma de diálogo. Isso significa que os diálogos devem ser formados entre os defensores do pós-estruturalismo, do pós-pós-estruturalismo, dos métodos mistos, e do SBR (Jackson; Mazzei, 2012). Essas quatro principais comunidades interpretativas precisam desenvolver formas de comunicação entre elas e de aprendizado uma com a outra.

Isso significa que devemos expandir o tamanho da nossa tenda; de fato precisamos de uma tenda maior! Não podemos lutar um com o outro. Os estudiosos de métodos mistos estudaram cuidadosamente os vários avanços diferentes da árvore pós-estrutural. $\mathrm{O}$ mesmo não pode ser dito para os pós-estruturalistas e pós-pós-estruturalistas. Tampouco podemos permitir que os argumentos da comunidade SBR nos dividam.

Devemos aprender com os conflitos paradigmáticos dos anos 80 para não sobrepujarmos, não nos envolvermos em polêmicas e não nos tornarmos auto satisfeitos. Precisamos desenvolver e trabalhar com nossos próprios conceitos de ciência, conhecimento e pesquisa de qualidade. Precisamos lembrar aos pós-positivistas ressurgentes que seus critérios de bom trabalho se aplicam apenas ao trabalho dentro do seu paradigma, não no nosso.

Ao longo das duas últimas décadas, os pós-estruturalistas lutaram muito para reivindicar um espaço interpretativo para investigação que questionou as normas de objetividade, a ênfase na complexidade, os processos interpretativos subjetivos, a performance, a textualidade, a diferença, a incerteza, a política, o poder e a investigação como um processo tanto moral como científico (ver Lather, 2007). Esses entendimentos, como estruturas obstinadas, não devem ser comprometidos. Eles são nós (knots) em nosso "lenço interpretativo".

Além disso, não podemos simplesmente apagar as diferenças entre pesquisa quantitativa e qualitativa, de departamentos quantitativos e qualitativos e de seus programas de treinamento de pós-graduação. A especialização em discursos ainda é um requisito. A investigação qualitativa é um campo enorme, que não é facilmente dominado a partir de um ou dois cursos generalistas (ver Eisenhart \& DeHaan, 2005). Um modelo de competência mínima de bilinguismo metodológico parece superficial e talvez, até mesmo, impraticável.

\section{Prosseguindo com Diálogos do Novo Paradigma}

Quero voltar aos temas descritos no ensaio de 1990 de Guba, "Manter o diálogo" (1990b). Este ensaio enumera 10 temas emergentes e três itens da agenda da "Conferência Paradigmática Alternativa" de 1989, registrada em Guba (1990a). Eu acredito que esses temas e itens da agenda podem nos guiar hoje. Afirmo com injunções, ou teses:

Tese 1: é necessário que haja uma maior abertura para as críticas de paradigmas alternativos.

Tese 2: é necessário que proponentes de paradigmas alternativos deixem de ser tão confrontantes.

Tese 3: devem ser explorados os caminhos para um diálogo frutífero entre e através 
de paradigmas.

Tese 4: as representações simplistas dos paradigmas mais recentes (e mais antigos) precisam ser evitadas. Isso ajudará a resolver a confusão.

Tese 5: complexidade e interconexão, não simplicidade, são inevitáveis (Guba, 1990b, p.337).

Tese 6: as teses de comensurabilidade da forma que são aplicadas a paradigmas e métodos, precisam ser revistas. $\mathrm{O}$ que se ganhou e o que se perdeu com estas duas teses?

Tese 7: Uma mudança nas posturas paradigmáticas envolve uma odisseia pessoal; isto é, cada um de nós tem uma história pessoal com nosso paradigma preferido e isso precisa ser honrado.

Tese 8: As três principais comunidades interpretativas (pós-estrutural, métodos mistos, SBR) devem aprender a cooperar e trabalhar um com o outro. Isto é assim porque o domínio do paradigma envolve controle sobre contratações, tenure, treinamento, financiamento, publicação, status e legitimação (Guba, 1990b, págs. 374).

Tese 9: Há uma necessidade de conferências que permitam que acadêmicos de paradigmas competidores se encontrem face a face e interajam. O Congresso Internacional de Investigação Qualitativo (International Congress of Qualitative Inquiry - Icqi.org) é uma tentativa de resolver esta necessidade.

Tese 10: A complexidade do campo de pesquisa qualitativa precisa ser honrada. A polarização e o elitismo precisam ser evitados. Em conferências e congressos, as comunidades de múltiplas línguas precisam ser representadas. O diálogo entre pessoas e comunidades interpretativas é crítico.

\section{Em Direção ao Futuro}

Três itens da agenda surgiram da Conferência de 1989. Eles podem ser trazidos à tona na segunda década deste novo século. Eles oferecem um framework para ação e colaboração. Precisamos formar alianças estratégicas e táticas. Precisamos formar redes interativas entre comunidades interpretativas.

A Agenda Intelectual: A comunidade global de investigação qualitativa precisa de eventos anuais, onde pode lidar com os problemas e questões que enfrentam neste momento histórico. Esses eventos devem ser internacionais, nacionais, regionais e locais. Eles podem ser realizados em conjunto com "universidades, sistemas escolares, sistemas de saúde, sistemas de justiça juvenil e similares" (Guba, 1990b, p. 376) ${ }^{3}$.

A Agenda Ativista: A comunidade precisa desenvolver "contatos sistemáticos com figuras políticas, a mídia (...) a imprensa profissional e com profissionais como professores, profissionais de saúde, assistentes sociais, [e] funcionários do governo" (p. 376). O ativismo inclui (a) mostrar como o trabalho qualitativo aborda questões de política social, (b) criticar diretrizes éticas ordenadas pelo governo federal para pesquisa de sujeito humano, e (c) criticar modos de ciência e pesquisa positivistas ultrapassados.

\footnotetext{
${ }^{3}$ Em 07 de maio de 2005, no ultimo dia do ICQI, a International Association of Qualitative Inquiry (IAQI) foi fundada em Urbana, Illinois, EUA. A IAQI é a primeira associação internacional unicamente dedicada para a promoção acadêmica, a representação e o desenvolvimento global da pesquisa qualitativa. Nesse momento, a IAQI tem 1500 delegados de 60 nações ao redor do mundo. Estabeleceu afiliações profissionais com mais de 50 locais de colaboração na Oceania, África, Américas do Sul e do Norte, Caribe, Europa, Oriente Médio, Japão, Korea e China (veja icqi.org). A newsletter do IAQI tem periodicidade trimestral, assim como o seu periódico, International Review of Qualitative Research.
} 
A Agenda Operacional: os pesquisadores qualitativos são encorajados a se engajar na autoaprendizagem e na autocrítica, para se ressocializarem, se necessário. Seus objetivos devem incluir a criação de relacionamentos produtivos com associações profissionais, periódicos, formuladores de políticas e financiadores (p. 376). Representantes de várias associações profissionais diferentes precisam ser reunidos.

\section{Em Conclusão}

Um dos principais objetivos é criar um espaço seguro onde os autores, professores e estudantes estejam dispostos a correr riscos, a transitar entre o pessoal e o político, e o biográfico e o histórico. Sob este quadro, nos ensinamos uns aos outros. Nós resistimos aos limites raciais, sexuais e de classe para alcançarmos o dom da liberdade; o dom do amor, do autocuidado; o dom do empoderamento, ensinando e aprendendo a transgredir. Falamos sobre experiências dolorosas, momentos em que a raça, gênero, classe e sexualidade se cruzam. Nós assumimos esses riscos porque criamos espaço seguro para tais atividades - desde salas de aula, a sessões de conferência, páginas de periódicos e em nossos livros - e a recompensa é imensa. Estamos livres nestes espaços para avançar em novos espaços, em novas identidades, novos relacionamentos e novas formas radicais de conhecimento acadêmico.

Trata-se de uma pedagogia centrada na performance que utiliza atuação, etnodrama e teatro social como métodos de investigação, como formas de auto etnografia e como métodos de compreensão (Denzin, 2014, 2017). Histórias pessoais (mystory), performance, etnodrama e teatro da realidade são formas de se fazerem visíveis as estruturas opressivas da cultura racismo, homofobia, sexismo (Saldaña, 2005, 2011). A performance desses dramas auto etnográficos torna-se uma ferramenta para documentar a opressão, um método para entender os significados da opressão e uma forma de promulgar uma política de possibilidade.

O modelo pedagógico e teatral que ofereço é colaborativo. Ele está localizado em uma comunidade moral criada a partir das interações e experiências que ocorrem dentro e fora das paredes da sala de seminários. Neste espaço seguro, os acadêmicos se juntam no terreno da justiça social. Embora isso seja feito nos espaços sagrados e seguros do discurso colaborativo, o medo da crítica e da incompreensão está sempre presente. Quando eles ocorrem, buscamos as pedagogias do perdão.

Teatro Social. Através da performance, o teatro social ajuda as pessoas a traduzirem os problemas privados em questões públicas; isto é, em representações que podem ser usadas para mobilizar ações sociais e análises críticas. Esta forma de teatro pode ser usada para influenciar a política pública. Pode contribuir para a justiça social das seguintes formas (Denzin, 2010, pp. 24-25):

1. Pode ajudar a identificar diferentes definições de um problema onde pode ou não haver concordância de que a mudança é necessária.

2. Em tais situações, as premissas, muitas vezes desmentidas por fatos, que são realizadas por várias partes interessadas - formuladores de políticas, clientes, profissionais de saúde, profissionais on-line - podem ser representados através de atuação e diálogo, e mostrados corretos ou incorretos (Becker, 1967, p. 23).

3. Os pontos estratégicos de intervenção em situações sociais podem então ser identificados.

4. É possível sugerir "pontos de vista morais alternativos a partir dos quais o problema", a política e a situação podem ser interpretadas e avaliadas (ver Becker, 1967, pp. 23-24). O modelo de teatro social sugere que as situações problemáticas devem sempre ser julgadas pelo ponto de vista das pessoas mais diretamente afetadas.

5. Os limites dos procedimentos de auditoria neoliberais podem ser expostos. A ênfase na singularidade de cada vida sustenta o caso individual como a medida da efetividade 
de qualquer mudança proposta.

Perguntamos, esse evento de performance, esta instância de teatro social:

1. Expõe e neutraliza o "policial na cabeça"?

2. Presta testemunho de uma injustiça?

3. Cultiva a consciência crítica de raça, classe e gênero?

4. Usa remontagens históricas para subverter ideologias neoliberais oficiais opressivas?

5. Cura, empodera, respeita e cria solidariedade comunitária?

6. Recupera, aprimora e preserva a integridade, a estabilidade e a beleza de uma comunidade moral? (Leopold, 1949).

7. Promove o diálogo e uma ética comunitária feminista de esperança?

8. Dá às pessoas uma "linguagem" para confrontar a opressão no futuro.

9. Fala a atos de ativismo, de resistência, de rebelião, de resiliência, atos de indignação, a raiva justa daqueles que foram enganados e traídos pelos poderosos (Freire, 1998, p. 93).

A performance de teatro social aplicada oferece um método de compreensão do que se passa a sua volta. A performance torna-se uma forma de intervir, participar e colaborar com uma comunidade moral, ajudando, com esperança, a mudar o mundo de maneiras positivas (Thompson \& Schechner, 2004, p. 16).

As vidas e histórias que escutamos e estudamos são dadas a nós sob uma promessa, sendo essa promessa a proteção daqueles que as compartilham conosco. E, em troca, esse compartilhamento nos permitirá escrever documentos de vida que falam sobre a dignidade humana, o sofrimento, as esperanças, os sonhos, as vidas adquiridas e as vidas perdidas pelas pessoas que estudamos. Esses documentos se tornarão testemunhos da capacidade do ser humano de suportar, prevalecer e triunfar sobre as forças estruturais que ameaçam a qualquer momento aniquilar a todos nós. Se fomentarmos a ilusão de que entendemos quando não entendemos, ou que encontramos vidas significativas e coerentes onde nenhuma existe, então nos comprometemos com uma prática cultural que é simplesmente tão repressiva quanto o mais repressivo dos regimes políticos.

A pesquisa qualitativa crítica está sob ataque. Acadêmicos qualitativos lutam para obter o tenure, suas pesquisas são muitas vezes subfinanciadas, os periódicos em que publicam recebem baixa pontuação de impacto. Acadêmicos ao redor do mundo, dentro e fora da academia, lutam contra as práticas regulatórias do neoliberalismo. Precisamos destacar, questionar e resistir a essas práticas; nos engajarmos em uma política de ativismo de prós e contras; formar coalizões; e nos envolvermos no debate sobre como os pesquisadores qualitativos podem resistir às pressões do neoliberalismo. Devemos travar batalhas pela tenure, contestar as métricas de accountability neoliberal (fatores de impacto de periódicos, avaliações de professores, pontuação de financiamento da pesquisa), enfrentar os ataques à liberdade de expressão e ameaças à governança compartilhada.

Os acadêmicos devem se unir para celebrar a comunidade, experimentar metodologias tradicionais, novas e com novas tecnologias de representação. Juntos procuramos desenvolver diretrizes e exemplos sobre questões de ativismo, investigação e justiça social. Nós compartilhamos um compromisso para mudar o mundo, para se envolver no trabalho ético que faça uma diferença positiva. Como acadêmicos críticos, nossa tarefa é trazer o passado e o futuro para o presente, o que nos permite envolver pedagogias utópicas realistas de esperança. 


\section{Referências}

Becker, H. S. (1967). Whose side are we on? Social Problems, 14, 239-247.

Bloom, L. R. (2009). Introduction: Global perspectives on poverty and social justice. International Studies of Qualitative Studies in Education, 22, 253-261.

Bloom, L. R., \& Sawin, P. (2009). Ethical responsibilities in feminist research: Challenging ourselves to do activist research with women in poverty. International Studies of Qualitative Studies in Education, 22, 333-351.

Clough, P. T. (2000). Comments on setting criteria for experimental writing. Qualitative Inquiry, 6, 278-291.

Denzin, N. K. (2010). The qualitative manifesto. Walnut Creek, CA: Left Coast Press.

Denzin, N. K. (2013). The death of data. Cultural Studies $\leftrightarrow$ Critical Methodologies, 13, 353356.

Denzin, N. K. (2014). Interpretive autoethnography (2nd ed.). Thousand Oaks, CA: SAGE.

Denzin, N. K. (2015). What is critical qualitative inquiry? In G. Cannella, M. Pérez, \& P. Pasque (Eds.), Critical qualitative inquiry: Foundations and futures (pp. 31-50). Walnut Creek, CA: Left Coast Press.

Denzin, N. K. (2017). Performance [auto] ethnography: Critical pedagogy and the politics of culture, 2.e. New York: Routledge.

Downing, D. B. (1987). Deconstruction's scruples: The politics of enlightened critique. Diacritics, 17, 66-81.

Du Bois, W. E. B. (1901). The problem of the twentieth century is the problem of the color line. In D. S. Green \& E. Driver (Eds.), W. E. B. Du Bois on sociology and the black community (pp. 281-289). Chicago, IL: University of Chicago Press.

Eisenhart, M., \& DeHaan, R. L. (2005). Doctoral preparation of scientifically based education research. Educational Researcher, 34(4), 3-14.

Eisenhart, M., \& Jurow, A. S. (2011). Teaching qualitative research. In N. K. Denzin \& Y. S. Lincoln (Eds.), Handbook of qualitative research (4th ed., pp. 699-714). Thousand Oaks, CA: SAGE.

Faulkner, W. (1967). Address upon receiving the Nobel Prize for literature. In M. Cowley (Ed.), The portable Faulkner (Rev. ed. pp. 723-724). New York, NY: Viking Press.

Freire, P. (1998). Pedagogy of freedom: Ethics, democracy, and civic courage (P. Clarke, Trans.). Boulder, CO: Roman \& Littlefield.

Garoian, C. R., \& Gaudelius, Y. M. (2008). Spectacle pedagogy: Art, politics and visual culture. Albany: State University of New York Press.

Guba, E. G. (1990a). The alternative paradigm dialog. In E. C. Guba (Ed.), The paradigm dialog (pp. 17-30). Newbury Park, CA: SAGE.

Guba, E. G. (1990b). Carrying on the dialog. In E. Guba (Ed.), The paradigm dialog (pp. 368378). Thousand Oaks, CA: SAGE.

Guba, E., \& Lincoln, Y. S. (2005). Paradigmatic controver- sies, and emerging confluences. In N. Denzin \& Y. Lincoln (Eds.), Handbook of qualitative research, 3/e (pp. 191-216). Thousand Oaks, CA: SAGE. 
Hammersley, M. (2008). Questioning qualitative inquiry: Critical essays. Thousand Oaks, CA: SAGE.

Howe, K. R. (2004). A critique of experimentalism. Qualitative Inquiry, 10, 42-61.

Howe, K. R. (2009). Positivist dogma, rhetoric, and the education science question. Educational Researcher, 38(6), 428-440.

Jackson, A. Y., \& Mazzei, L. A. (2012). Thinking with theory in qualitative research: Viewing data across multiple perspec- tives. London, England: Routledge.

Koro-Ljungberg, M., \& MacLure, M. (2013). Provocations, re-un- visions, death and other possibilities of data. Cultural Studies $\leftrightarrow$ Critical Methodologies, 13, 219-222.

Lather, P. (2007). Getting lost: Feminist efforts toward a double (d) science. Albany: State University of New York Press. Leopold, A. (1949). A sand county almanac. New York, NY:

Oxford University Press. Luke, C., \& Gore, J. (Eds.). (1992). Feminists and critical pedagogy. New York, NY: Routledge.

Madison, D. S. (1998). Performances, personal narratives, and the politics of possibility. In S. J. Dailey (Ed.), The future of performance studies: Visions and revisions (pp. 276-286). Annadale, VA: National Communication Association.

Marcus, G. E. (2009). Introduction: Notes toward an ethnographic memoir of supervising graduate research through anthropol- ogy's decades of transformation. In J. D. Faubion \& G. E. Marcus (Eds.), Fieldwork is not what it used to be: Learning anthropology's method in a time of transition (pp. 1-34). Ithaca, NY: Cornell University Press.

Maxwell, J. A. (2004). Reemergent scientism, postmodernism, and dialogue across differences. Qualitative Inquiry, 10, 35-41.

McLaren, P., \& Kincheloe, J. L. (Eds.). (2007). Critical pedagogy: Where are we now? New York, NY: Peter Lang.

Mertens, D. M., Holmes, H. M., \& Harris, R. L. (2009). Transformative research and ethics. In D. M. Mertens \& P. E. Ginsberg (Eds.), The handbook of social research ethics (pp. 85101). Thousand Oaks, CA: SAGE.

Ryan, K. E., \& Hood, L. (2004). Guarding the castle and opening the gates. Qualitative Inquiry, 10, 79-95.

Saldana, J. (2005). An introduction to ethodrama. In J. Saldana (Ed.), Ethnography: An anthology of realty theatre (pp. 1-36). Walnut Creek, CA: AltaMira.

Saldana, J. (2011). Ethnotheatre: Research from page to stage. Walnut Creek, CA: Left Cost Press.

St. Pierre, E. A. (2011). Post qualitative research: The critique and the coming after. In N. K. Denzin \& Y. S. Lincoln (Eds.), Handbook of qualitative research (4th ed., pp. 611-626). Thousand Oaks, CA: SAGE.

Teddlie, C., \& Tashakkori, A. (2003. Major issues and controver- sies in the use of mixed methods in the social and behavioral sciences. In A. Tashakkori \& C. Teddlie (Eds.), Handbook of mixed-methods in social and behavioral research (pp. 3-50). Thousand Oaks, CA: SAGE.

Thompson, J., \& Schechner, R. (2004). Why "social theatre"? The Drama Review, 48(3), 1116. 
Vidich, A. J., \& Lyman, S. M. (1994). Qualitative methods: Their history in sociology and anthropology. In N. K. Denzin \& Y. S. Lincoln (Eds.), Handbook of qualitative research (pp. 23- 59). Thousand Oaks, CA: SAGE.

Weems, M. M. (2002). I speak from the wound in my mouth. New York, NY: Peter Lang.

\section{Nota do autor}

Este artigo repete e amplia os argumentos em Denzin (2017a, 2015, 2010).

\section{Nota do Editor}

Este artigo é uma tradução autorizada pelo autor, realizada por Diogo Vera de Carvalho, com revisão técnica de Fernanda Filgueiras Sauerbronn e João Felipe Rammelt Sauerbronn. Ver original em Qualitative Inquiry, 2017, 23(1), 8-16. DOI: 10.1177/1077800416681864 qix.sagepub.com 